\title{
Short communication: Interaction of bovine milk protein with chlorpyrifos
}

\author{
Ying Lv, Xuefen Li, Zongyi Wang, Han Zheng, Qi Zhang, Ran Huo, Xiangning Chen, and Tao Han ${ }^{1}$ \\ Beijing Laboratory of Food Quality and Safety, Beijing Key Laboratory of Agricultural Product Detection and Control of Spoilage Organisms and \\ Pesticide Residue, College of Food Science and Engineering, Beijing University of Agriculture, Beijing, China 102206
}

\begin{abstract}
Dairy products are considered as nutrient-dense foods and consumed by many people in western countries, as well as an increasing number of Asian people. Excessive and frequent application of pesticides on vegetables and fruits leads to a potential health hazard to consumers. The organophosphate insecticide chlorpyrifos has been reported to bind with human and bovine serum albumin. Thus, it is necessary to explore the interaction between food protein and chlorpyrifos. In this study, equilibrium dialysis and fluorescence spectra were used to demonstrate binding of milk proteins to chlorpyrifos. The amount of milk protein bound was $0.03 \pm 0.01$ $\mathrm{mg} / \mathrm{g}$. Moreover, the milk protein-chlorpyrifos complexes were stable at $\mathrm{pH} 3.5$ to 9.5 and ion concentrations from 0.1 to $1.0 \mathrm{M}$. The amount of chlorpyrifos bound to milk proteins decreased to $50 \%$ after being in vitro digested by pepsin and trypsin. The results showed that the interaction between food proteins and the pesticide might partially remove the insecticide and reduce the concentration of pesticide absorbed into the blood and, thus, alleviate the corresponding toxicity.
\end{abstract}

Key words: chlorpyrifos, skimmed milk, binding, stability

\section{Short Communication}

Chlorpyrifos [O,O-diethyl- $O$-(3,5,6-trichloro-2-pyridinyl) phosphorothioate] is an organophosphorous insecticide that is widely used for insect and pest control on grain, cotton, fruits, and vegetables. Recently, excessive and frequent application of pesticides on greenhouse vegetables has led to acute or chronic dietary exposure to chlorpyrifos residues in food (Bolognesi and Morasso, 2000; Carvalho, 2006). Many research studies have focused on the interaction between human serum albumin (HSA) or BSA and drugs. It was reported that chlorpyrifos could bind with blood protein (Sultatos et al., 1984; Cui et al., 2006). Binding to HSA

Received October 9, 2013.

Accepted January 1, 2014.

${ }^{1}$ Corresponding author: taohan00@163.com or BSA effectively decreases the concentration of free insecticides in the blood and, as a consequence, affects the duration and intensity of their effects in the body. However, before chlorpyrifos is absorbed into the blood, it coexists with food components, such as protein, carbohydrates, minerals, and fat. These components might interact with pesticides. Also, processing conditions and intestinal digestion may affect chlorpyrifos binding with food components. Thus, it is necessary to explore the interaction between food components and chlorpyrifos to determine if the binding between them could partially remove the insecticide and, thus, reduce its toxicity.

Dairy products are an important component of diet for western people. Recently, the consumption of milk products in Asian countries, such as China, Japan, and South Korea, has been gradually increased (Dong, 2006). Dairy products contain a significant amount of protein, lactose, essential vitamins, and minerals and are, therefore, commonly referred to as nutrient-dense and healthy foods (Drewnowski, 2005; Heaney, 2009; Hilpert et al., 2009; Kris-Etherton et al., 2009). The protein content in bovine milk is about 3 to $4 \%$, which is composed of casein and whey protein. Both proteins were reported to have binding ability to minerals, such as iron and calcium (Vegarud et al., 2000). However, the interaction between milk protein and pesticides is still unclear. Hence, in the current study, equilibrium dialysis and fluorescence spectra were used to evaluate the binding characteristics of milk protein with chlorpyrifos. The stability of the milk protein-chlorpyrifos complexes was also discussed to evaluate whether the interaction between milk protein and chlorpyrifos could reduce the residues being absorbed into the body.

Bovine milk was a gift from the experiment station at the Beijing University of Agriculture (Beijing, China). The widely used organophosphorous pesticide chlorpyrifos $(100 \mu \mathrm{g} / \mathrm{mL}$, wt/vol) was obtained from the Agro-Environmental Protection Institute (Tianjin, China). The dialysis membrane had a molecular weight cutoff of $10 \mathrm{kDa}$ (Viskase Co., Darien, IL).

The fresh bovine milk was centrifuged at 3,000 $\times g$ for $20 \mathrm{~min}$ at room temperature. After that, fat was removed and the skim milk was lyophilized. The con- 
centration of protein was determined by the method of Bradford (1976). Bovine serum albumin was used as a reference protein.

Equilibrium dialysis was used to measure the amount of chlorpyrifos bound to milk protein. The lyophilized skim milk powder was dissolved in $0.05 \mathrm{M}$ Tris- $\mathrm{HCl}$ buffer ( $\mathrm{pH} 7.4$ ) to reach the final protein content of 20 $\mathrm{mg} / \mathrm{mL}$ (wt/vol). The prepared skim milk solution (1 $\mathrm{mL}$ ) was added to $100 \mu \mathrm{L}$ of $10 \mu \mathrm{g} / \mathrm{mL}$ chlorpyrifos. After being mixed, the solutions were transferred to a dialysis bag and dialyzed in $500 \mathrm{~mL}$ of $0.05 \mathrm{M}$ Tris- $\mathrm{HCl}$ buffer ( $\mathrm{pH} 7.4$ ) at room temperature. The chlorpyrifos concentration eventually reached a stable value, which was taken as the concentration of chlorpyrifos bound to protein. The dialysate was changed at $3 \mathrm{~h}$ and samples were collected at 2, 4, and $6 \mathrm{~h}$. Changes in chlorpyrifos concentration were monitored using GC-MS. The buffer without skim milk was added to the same amount of chlorpyrifos in the dialysis bag and was used as a control.

The dialyzed sample was extracted in $15 \mathrm{~mL}$ of acetonitrile with $6 \mathrm{~g}$ of $\mathrm{NaCl}$ added, and then centrifuged $(3,000 \times g$ for $20 \mathrm{~min}$ at room temperature). The organic phase was collected. After that, the same amount of acetonitrile was used to extract chlorpyrifos again. The organic phase was collected together and evaporated to dryness in a rotary evaporator (RE-52AA, Shanghai Qingpu Huxi Instrument Co., Shanghai, China) under reduced pressure at $45^{\circ} \mathrm{C}$ for about $10 \mathrm{~min}$, and then reconstituted in $1 \mathrm{~mL}$ of acetone. Subsequently, this solution was filtered and injected into a GC-MS system (7890/5975C; Agilent Technologies Inc., Santa Clara, $\mathrm{CA})$. The following analytical conditions were used: capillary column: DB-5MS $(30 \mathrm{~m} \times 0.25 \mathrm{~mm} \times 0.25-$ $\mathrm{mm}$ film thickness; Agilent J\&W Scientific, Folsom, $\mathrm{CA})$; rate of carrier gas: $1.0 \mathrm{~cm}^{3} / \mathrm{min}$; sample volume: 1 $\mu \mathrm{L}$; injector temperature: $280^{\circ} \mathrm{C}$; temperature program: $50^{\circ} \mathrm{C}$ for $4 \mathrm{~min}$, increasing to $190^{\circ} \mathrm{C}$ at $15^{\circ} \mathrm{C} / \mathrm{min}$, and then increasing to $275^{\circ} \mathrm{C}$ at $10^{\circ} \mathrm{C} / \mathrm{min}$ and held for 15 min; ionization: $\mathrm{E}+70 \mathrm{eV}$; data collection method: selected ions model (SIM), $m / z=314,286,258$, and 199; interface temperature: $280^{\circ} \mathrm{C}$; temperature of source: $230^{\circ} \mathrm{C}$; and temperature of quadrupole: $150^{\circ} \mathrm{C}$.

Fluorescence spectra were measured in an LS-55 spectrofluorophotometer (PerkinElmer Ltd., Beaconsfield, UK) with a 1-cm quartz cell. The excitation and emission bandwidths were $5 \mathrm{~nm}$. The excitation wavelength used was $280 \mathrm{~nm}$ and the emission was read at 200 to $500 \mathrm{~nm}$. The analysis of interaction between milk protein and chlorpyrifos was performed on fluorometric titration. A 2-mL solution containing $20 \mu \mathrm{g}$ of skim milk/mL of $0.05 M$ Tris-HCl buffer (pH 7.4) was titrated by successive additions of $10 \mu \mathrm{L}$ of chlorpyrifos solution $(1 \mu \mathrm{g} / \mathrm{mL})$ each time to obtain different ratios of chlorpyrifos:protein, and thus the fluorescence intensity was measured.

The effect of $\mathrm{pH}$ and salt concentration on the binding stability of chlorpyrifos to skim milk protein was investigated with the equilibrium dialysis method. Dialysate buffers with different $\mathrm{pH}$ values were as follows: (a) $0.05 M$ sodium acetate-acetic acid buffer at $\mathrm{pH} 3.5$, (b) $0.05 \mathrm{M}$ sodium acetate-acetic acid buffer at $\mathrm{pH} 5.5$, (c) $0.05 M$ Tris- $\mathrm{HCl}$ buffer at $\mathrm{pH} 7.5$, and (d) $0.05 M$ Tris- $\mathrm{HCl}$ buffer at $\mathrm{pH}$ 9.5. All of these buffers contained $0.1 \mathrm{M} \mathrm{NaCl}$. Dialysate buffers with different salt concentrations were as follows: $0.05 \mathrm{M}$ Tris- $\mathrm{HCl}$ buffer at pH 7.4, containing $0.1,0.5$, or $1.0 \mathrm{M} \mathrm{NaCl}$.

The stability of the milk protein-chlorpyrifos complexes was evaluated with in vitro digestion by pepsin and trypsin. The above equilibrium dialysis method was used and the solution in the dialysis bag was considered as the complex. First, milk protein-chlorpyrifos complexes were hydrolyzed with pepsin. The $\mathrm{pH}$ of the complexes solution was adjusted to 2.0 with $5 \mathrm{M} \mathrm{HCl}$. After that, pepsin (enzyme:substrate $=1: 100 ; \mathrm{wt} / \mathrm{wt}$ ) was added to hydrolyze the complexes at $37^{\circ} \mathrm{C}$ for $1 \mathrm{~h}$. Then, this solution was transferred to a dialysis bag to dialyze for $6 \mathrm{~h}$ to remove free chlorpyrifos caused by hydrolysis, and the concentration of bound chlorpyrifos was measured with GC-MS. Second, milk protein-chlorpyrifos complexes were hydrolyzed with both pepsin and trypsin. After being hydrolyzed by pepsin for $1 \mathrm{~h}$, the $\mathrm{pH}$ of this solution was adjusted to $\mathrm{pH} 7.0$ with 5 $M \mathrm{NaOH}$, and trypsin (enzyme:substrate $=1: 100$; wt $/$ wt) was added to hydrolyze the complexes for another $2 \mathrm{~h}$ at $37^{\circ} \mathrm{C}$. The hydrolyzed milk protein-chlorpyrifos complexes were then dialyzed as above and the remaining chlorpyrifos of the complexes was measured.

The experiments were repeated 2 times. All of the experiments included 3 to 4 replicates. Before statistical analyses, data were checked for normality and homogeneity. The means and standard deviations for each treatment group were calculated in all experiments. The significance of difference between the means was evaluated by Scheffé's test after one-way ANOVA using SPSS software (SPSS Inc., Chicago, IL). Differences of $P<0.05$ were considered statistically significant.

Figure 1 shows the relative changes of chlorpyrifos concentration in the dialysis bag during the equilibrium dialysis when skim milk was added. The chlorpyrifos content displayed a rapid decrease from 0 to $2 \mathrm{~h}$ of dialysis, and reached a stable value during the subsequent $4 \mathrm{~h}$. However, the control without skim milk was not detected with chlorpyrifos concentration. During dialysis, free chlorpyrifos was selectively removed from the solution through a semipermeable membrane with a molecular-weight cutoff of $10 \mathrm{kDa}$. Thus, the chlorpyrifos concentration of the solution in the dialysis 


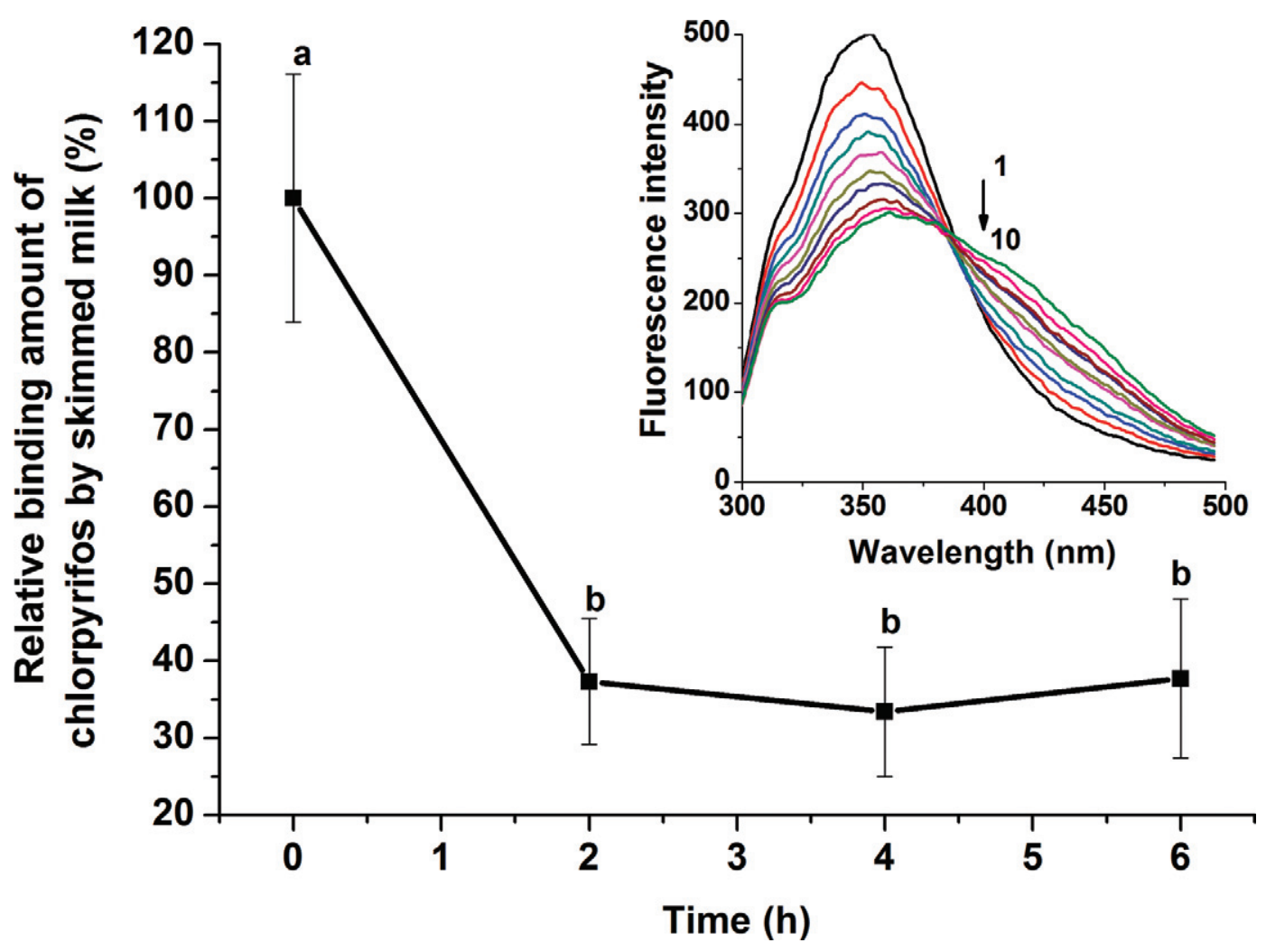

Figure 1. Relative binding amount of chlorpyrifos by skim milk over time. Error bars represent standard deviation from the mean $(\mathrm{n}=3-4)$. Bars with different letters differ significantly $(P<0.05)$. Color version available in the online PDF.

bag measured by GC-MS was that of the chlorpyrifos bound in skim milk. Usually, the main components in skim milk are protein and lactose. During equilibrium dialysis, the lactose content decreased because of diffusion through semipermeable membranes, driven by a concentration gradient across the membrane. However, because of its high molecular weight, milk protein (casein and whey protein) cannot go through the membrane. Thus, the chlorpyrifos content of the solution in dialysis bag could be that of the chlorpyrifos bound to milk protein, which was measured as $0.03 \pm 0.01$ $\mathrm{mg} / \mathrm{g}$.

Subsequently, the interaction between skim milk and chlorpyrifos was investigated using fluorescence spectroscopy. Fluorescence spectra have been widely used to study the interaction between low-molecularweight drugs and proteins ( $\mathrm{Hu}$ et al., 2005; Zhang et al., 2008). Tryptophan residue in protein emits strong fluorescence intensity when excited at a wavelength of $280 \mathrm{~nm}$ and, thus, is used as a natural probe of intrinsic fluorescence (Brown and Royer, 1997; Vivian and Callis, 2001). As presented in Figure 1 (inset), the maximum intrinsic fluorescence of skim milk protein occurred at $353 \mathrm{~nm}$ when excited at $280 \mathrm{~nm}$, whereas a remarkable decrease in the fluorescence of milk protein was observed with the addition of chlorpyrifos. Also, a red shift in the maximum emission wavelength was shown with an increase in the chlorpyrifos:protein ratio, which suggests a less hydrophobic microenvironment of tryptophan residue (He et al., 2008; Bi et al., 2009). Many research studies have focused on the interaction of pesticides (chlorpyrifos, bromadiolone, and methyl parathion) with HSA or BSA (Silva et al., 2004; Deepa and Mishra, 2005; Cui et al., 2006). Binding of insecticide to the plasma protein reduces the concentration of free insecticide and then decreases the toxic action of the insecticide. However, little is known about the binding characteristics of food protein and chlorpyrifos. Skim milk contains about 3\% protein and is consumed by many people every day. Thus, the interaction between milk protein and chlorpyrifos might also decrease the concentration of pesticides in the body.

The milk protein and chlorpyrifos were bound in 0.05 $M$ Tris-HCl buffer ( $\mathrm{pH} 7.4$ ) and then dialyzed with dialysate buffers at different $\mathrm{pH}$ values for $6 \mathrm{~h}$. The solution in the dialysis bag was then transferred to measure the chlorpyrifos content using GC-MS. The results are shown in Figure 2A. It seems that the milk protein-chlorpyrifos complexes were relatively stable at different $\mathrm{pH}$ conditions. Also, no significant difference 

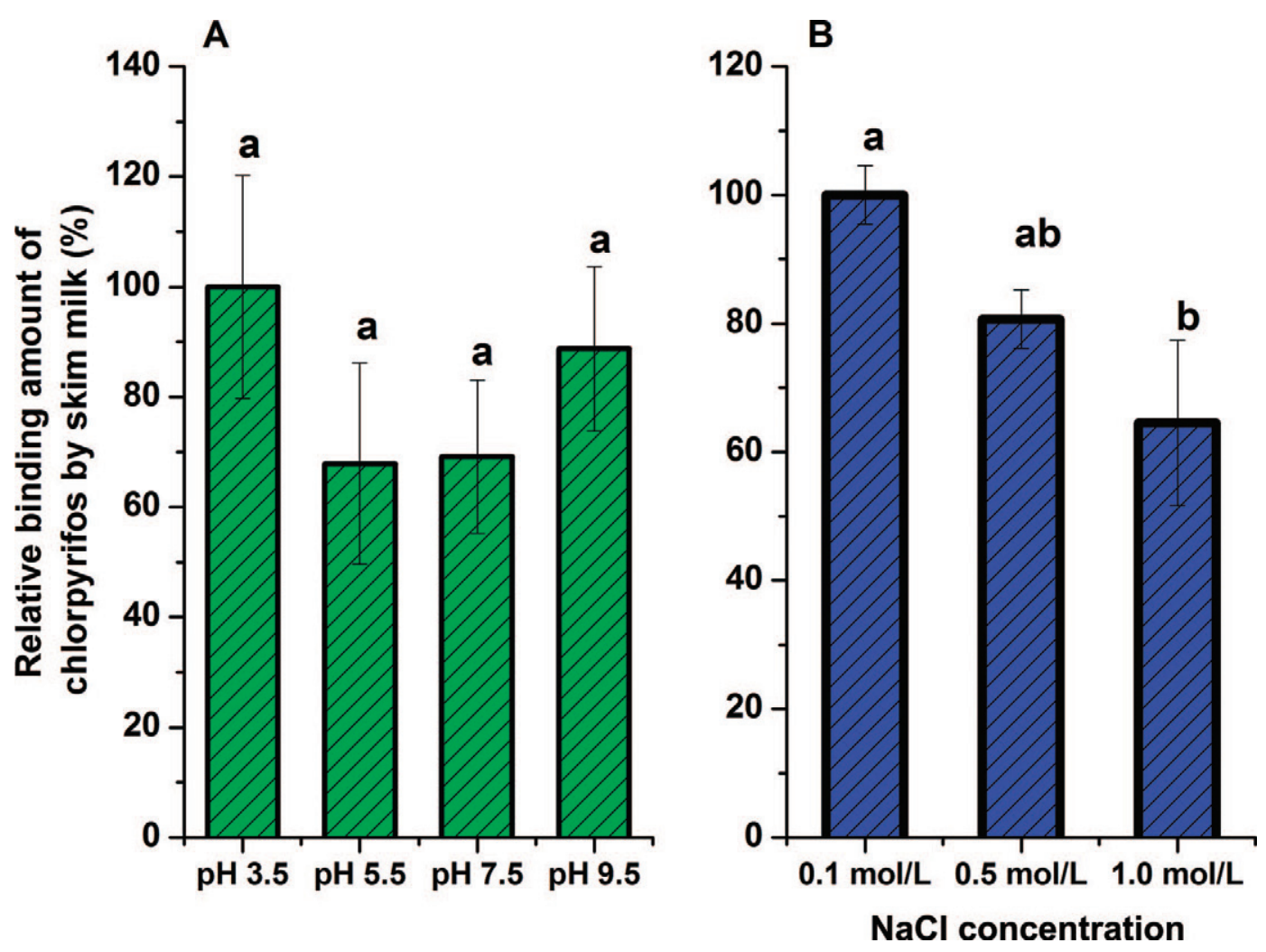

Figure 2. Relative binding amount of chlorpyrifos by skim milk at different $\mathrm{pH}$ conditions (A) and after being dialyzed in buffers containing different $\mathrm{NaCl}$ concentrations from 0.1 to $1.0 \mathrm{M}$ for $6 \mathrm{~h}(\mathrm{~B})$. Error bars represent standard deviation from the mean (n = 3-4). Bars with different letters differ significantly $(P<0.05)$. Color version available in the online PDF.

was observed among the complexes. The effect of ionic strength on stability of the complexes was investigated after being dialyzed in buffers containing different $\mathrm{NaCl}$ concentrations from 0.1 to $1.0 \mathrm{M}$ for $6 \mathrm{~h}$ (Figure 2B). A decreasing tendency was observed with an increase in salt concentration. It has been reported that 3 types of interactions exist between organophosphate compounds and albumin. The less-reactive phosphorothioates, such as parathion and chlorpyrifos, with characteristics of high hydrophobicity, can interact reversibly with albumin by hydrophobic interactions (Sultatos et al., 1984; Silva et al., 2004). As shown in Figure 1 (inset), a red shift of the maximum emission wavelength with increasing ratio of chlorpyrifos to protein presented a more hydrophilic environment of tryptophan residue, and a more hydrophobic condition obtained by adjustment of protein structure might then be provided for the interaction between milk protein and chlorpyrifos. From the results above, it seems that the hydrophobic interaction may drive the formation of the complexes. Also, the electrostatic interaction between the pesticide and protein played a relatively minor role in the formation of the complexes, considering the effect of ion concentration on the stability of the complexes.
The in vitro digestion with pepsin and trypsin was carried out to investigate the stability of the milk protein-chlorpyrifos complexes. From Figure 3, we can infer that hydrolysis by pepsin and trypsin could reduce the binding capacity of the milk protein with chlorpyrifos. No obvious difference existed between pepsin and trypsin. The stability decreased about 50\% compared with the original milk protein-chlorpyrifos complexes.

In summary, the results from the present study showed that milk protein could bind with chlorpyrifos by equilibrium dialysis and fluorescence spectra. Moreover, the milk protein-chlorpyrifos complexes were stable at $\mathrm{pH} 3.5$ to 9.5 and ion concentrations from 0.1 to $1.0 \mathrm{M}$. Hydrolysis with pepsin and trypsin decreased the stability of the complexes. This study brings new insight for better understanding the interaction between food protein and pesticides. However, further research needs to focus on the interaction between other kinds of insecticides with milk proteins.

\section{ACKNOWLEDGMENTS}

This work was supported by the Program on Detection and Control of Spoilage Organisms and Pesticide 


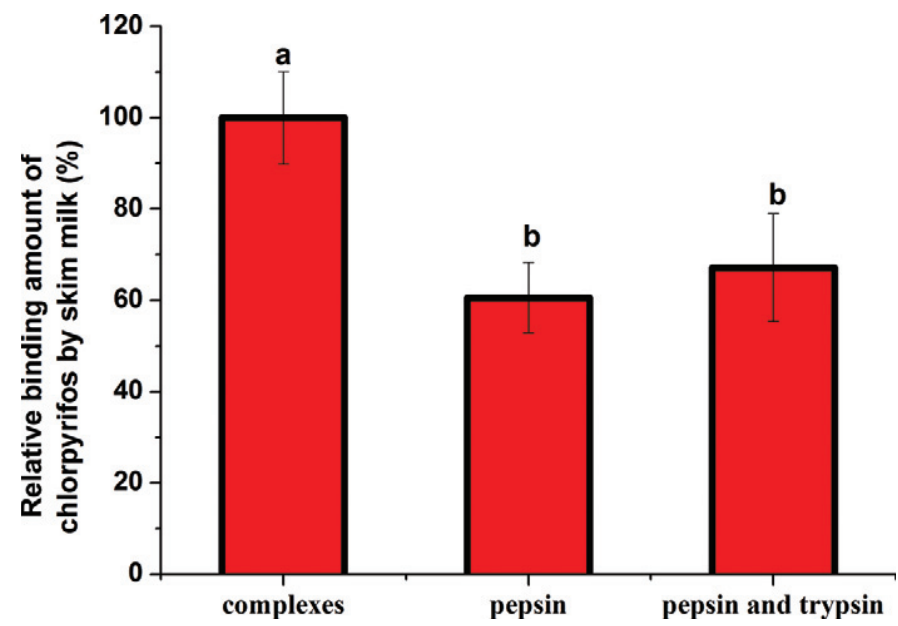

Figure 3. Relative binding amount of chlorpyrifos by skim milk for milk protein-chlorpyrifos complexes without digestion, after in vitro digestion with pepsin, and after in vitro digestion with pepsin and trypsin. Error bars represent standard deviation from the mean $(\mathrm{n}=$ $3-4)$. Bars with different letters differ significantly $(P<0.05)$. Color version available in the online PDF.

Residues in Agricultural Products (Beijing, China; PXM2012-014207-000011), Key Discipline Construction Program of Beijing Municipal Commission of Education (Beijing, China; PXM2013-014207-000057), and Program of Development and Their Bioactive Investigation of Functional Foods (Beijing, China; PXM2013014207-000048).

\section{REFERENCES}

Bi, S., Y. Sun, C. Qiao, H. Zhang, and C. Liu. 2009. Binding of several anti-tumor drugs to bovine serum albumin: Fluorescence study. J. Lumin. 129:541-547.

Bolognesi, C., and G. Morasso. 2000. Genotoxicity of pesticides: Potential risk for consumers. Trends Food Sci. Technol. 11:182-187.
Bradford, M. M. 1976. A rapid and sensitive method for the quantitation of microgram quantities of protein utilizing the principle of protein-dye binding. Anal. Biochem. 72:248-254.

Brown, M. P., and C. Royer. 1997. Fluorescence spectroscopy as a tool to investigate protein interactions. Curr. Opin. Biotechnol. 8:45-49.

Carvalho, F. P. 2006. Agriculture, pesticides, food security and food safety. Environ. Sci. Policy 9:685-692.

Cui, Y., J. Guo, B. Xu, and Z. Chen. 2006. Binding of chlorpyrifos and cypermethrin to blood proteins. Pestic. Biochem. Physiol. 85:110-114.

Deepa, S., and A. K. Mishra. 2005. Fluorescence spectroscopic study of serum albumin-bromadiolone interaction: Fluorimetric determination of bromadiolone. J. Pharm. Biomed. Anal. 38:556-563.

Dong, F. 2006. The outlook for Asian dairy markets: The role of demographics, income, and prices. Food Policy 31:260-271.

Drewnowski, A. 2005. Concept of a nutritious food: Toward a nutrient density score. Am. J. Clin. Nutr. 82:721-732

He, Y., Y. Wang, L. Tang, H. Liu, W. Chen, Z. Zheng, and G. Zou. 2008. Binding of puerarin to human serum albumin: A spectroscopic analysis and molecular docking. J. Fluoresc. 18:433-442.

Heaney, R. P. 2009. Dairy and bone health. J. Am. Coll. Nutr. 28:82S-90S.

Hilpert, K. F., S. G. West, D. M. Bagshaw, V. Fishell, L. Barnhart, M. Lefevre, M. M. Most, M. B. Zemel, M. Chow, A. L. Hinderliter, and P. M. Kris-Etherton. 2009. Effects of dairy products on intracellular calcium and blood pressure in adults with essential hypertension. J. Am. Coll. Nutr. 28:142-149.

Hu, Y.-J., Y. Liu, Z.-B. Pi, and S.-S. Qu. 2005. Interaction of cromolyn sodium with human serum albumin: A fluorescence quenching study. Bioorg. Med. Chem. 13:6609-6614.

Kris-Etherton, P. M., J. A. Grieger, K. F. Hilpert, and S. G. West. 2009. Milk products, dietary patterns and blood pressure management. J. Am. Coll. Nutr. 28:103S-119S.

Silva, D., C. M. Cortez, J. Cunha-Bastos, and S. R. W. Louro. 2004. Methyl parathion interaction with human and bovine serum albumin. Toxicol. Lett. 147:53-61.

Sultatos, L. G., K. M. Basker, M. Shao, and S. D. Murphy. 1984. The interaction of the phosphorothioate insecticides chlorpyrifos and parathion and their oxygen analogues with bovine serum albumin Mol. Pharmacol. 26:99-104.

Vegarud, G. E., T. Langsrud, and C. Svenning. 2000. Mineral-binding milk proteins and peptides; occurrence, biochemical and technological characteristics. Br. J. Nutr. 84:S91-S98.

Vivian, J. T., and P. R. Callis. 2001. Mechanisms of tryptophan fluorescence shifts in proteins. Biophys. J. 80:2093-2109.

Zhang, G., Q. Que, J. Pan, and J. Guo. 2008. Study of the interaction between icariin and human serum albumin by fluorescence spectroscopy. J. Mol. Struct. 881:132-138. 